OPEN ACCESS

Edited by:

Lizhen Huang,

Norwegian University of Science and

Technology, Norway

Reviewed by

Stanislav Martinat,

Institute of Geonics (ASCR), Czechia

K. P. Singh Parmar,

National Power Training Institute, India

${ }^{*}$ Correspondence:

Elisabetta Garofalo

elisabetta.garofalo@rse-web.it

Specialty section:

This article was submitted to

Sustainable Energy Systems and

Policies,

a section of the journal

Frontiers in Energy Research

Received: 08 May 2020 Accepted: 30 September 2020

Published: 11 November 2020

Citation:

Garofalo E, Giudici F and Guastella S (2020) A Methodological Framework for Fostering Renewable Investments on Photovoltaic in Small Italian Islands.

Front. Energy Res. 8:560251.

doi: 10.3389/fenrg.2020.560251

\section{A Methodological Framework for Fostering Renewable Investments on Photovoltaic in Small Italian Islands}

\author{
Elisabetta Garofalo*, Federico Giudici and Salvatore Guastella \\ Sustainable Development and Energy Sources Department, RSE Ricerca sul Sistema Energetico, Milano, Italy
}

In Italy, 19 small off-grid islands with a total resident population of about 50,000 inhabitants almost exclusively rely on carbon intensive diesel generators to produce electricity. As a consequence, high costs and greenhouse gas emissions, as well as low security of electricity supply make these islands economically and environmentally unsustainable. This paper proposes an integrated and comprehensive methodological framework for improving the sustainability of the small Italian islands through the introduction of renewable energy sources. The framework is composed of a prescriptive phase, where the renewable capacity targets to be ideally achieved and the most effective incentives for actually promoting renewable investments on photovoltaic are identified, and an assessment phase, where the effect of the incentives introduction is evaluated, providing policy recommendations for further promoting renewable investments. Results show that a relatively high renewable share can be ideally reached with low efforts in almost all the islands considered, and differentiated incentives for promoting investments are needed to account for the different geographical characteristics of each island. However, the analysis performed in the assessment phase shows that the decarbonization process is evolving very slowly and almost all the islands are far from reaching 2020 and, even more, 2030 capacity targets. The main reasons include the short time elapsed after the incentives introduction and a generalized lack of suitable sites for the deployment of photovoltaic plants, also due to the strict environmental constraints of these areas. Further actions to promote renewable development should go in the direction of fostering investments from private subjects and better harmonizing the energy and environmental objectives through a shared strategy for the enhancement of the sustainability of the island electricity systems.

Keywords: small Italian islands, islands decarbonization, photovoltaic, energy system sustainability, policy recommendations, renewable investments, incentives

\section{INTRODUCTION}

In Italy, 19 permanently inhabited small islands are completely disconnected from the national electricity grid and their energy system almost exclusively relies on carbon intensive diesel generators (Zuccaro and Guastella, 2001; Corsini et al., 2005). These islands, which have an area ranging from 1.4 to $85 \mathrm{~km}^{2}$ are located in the Mediterranean sea around Sicily (Egadi, Eolie and Pelagie archipelagos as well as Ustica and Pantelleria islands) and off the coast of Tuscany (Giglio and Capraia), Lazio (Ventotene and Ponza) and Apulia (Tremiti islands) (Figure 1). Capri island (off the 


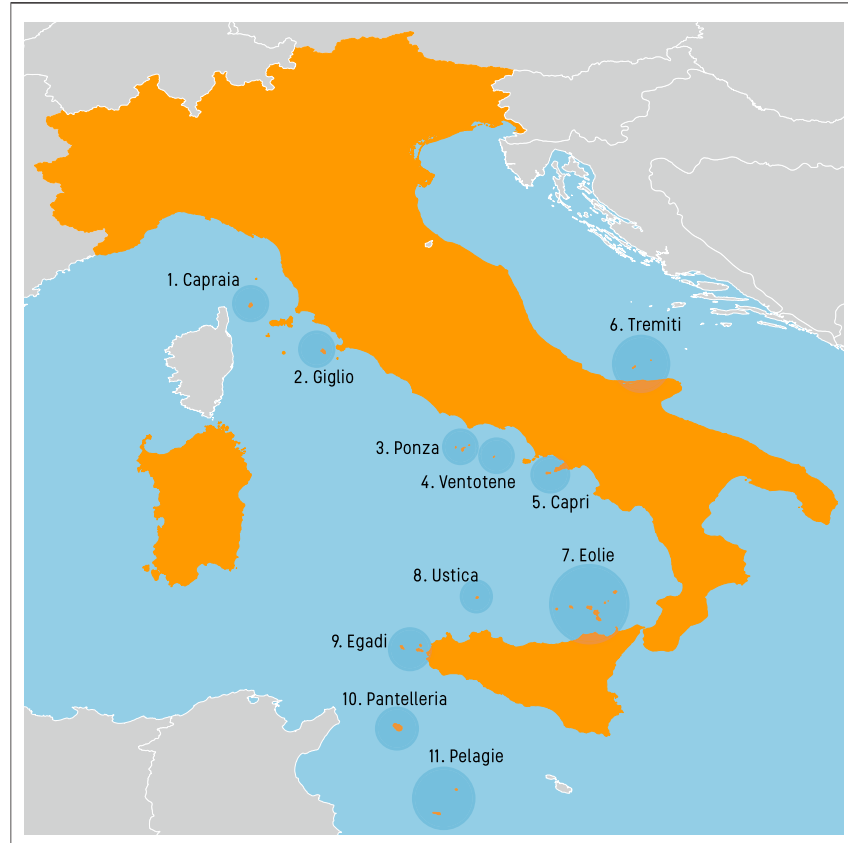

FIGURE 1 | Map of the small Italian islands non-interconnected to the national electricity grid. Numbers refer to the IDs reported in Table $\mathbf{1 .}$

coast of Campania), which represented the $20^{\text {th }}$ disconnected island at the time of the analyses reported in this paper, has been only recently connected to the national electricity grid.

Even if each of these islands is characterized by specific peculiarities, some common aspects shared by many small islands in the Mediterranean area make these systems strongly unsustainable from both an economic and an environmental point of view (Weisser, 2004; Franzitta et al., 2016). First of all, the great seasonal variability of the electricity demand, due to summer touristic fluxes, causes diesel generators to be oversized during the winter months (Kristoferson et al., 1985; Garofalo et al., 2014; Groppi et al., 2019). The high dependence upon remote supply of fuel, which is transported from the mainland by boat, contributes to very high power production costs (Kakazu et al., 1994; Gatta et al., 2018). Moreover, a structural lack of flexibility in balancing energy supply and demand typical of off-grid systems poses great challenges in controlling electricity grid parameters and assuring good quality energy services (Elbaset, 2011; Merino et al., 2012; Larsen et al., 2014). Finally, due to the lack of accessible and safe water sources, some of the islands have recently adopted desalination technologies to produce drinking water (Voivontas et al., 2003; Garofalo et al., 2014; Corsini and Tortora, 2017). With an electrical consumption that varies from $2-6$ to $7-14 \mathrm{kWh} / \mathrm{m}^{3}$ for membrane-based and thermal technologies, respectively (Ghalavand et al., 2015), the desalination process significantly impacts the electricity system, further increasing carbon emissions and the operating cost of the water-energy system (Kalogirou, 2005).

With the main goal of improving the sustainability of small islands, in the last few decades different studies have been carried out to provide guidelines and suggestions for shaping the energy transition from technologies based on fossil fuel to renewable energy sources (RES) (Tselepis et al., 2001; Blechinger et al., 2014, 2016; Zafirakis et al., 2016; Kougias et al., 2019). By exploiting the high renewable power potential given by islands' geographic location (namely wind and solar), the most widely adopted approach focuses on optimally designing hybrid energy systems, combining diesel generation with RES [e.g., photovoltaic (PV), wind] and storage technologies (i.e., batteries), in order to produce clean energy at lower costs (Ekren and Ekren, 2009; Ibrahim et al., 2010; Erdinc and Uzunoglu, 2012; Eras-Almeida and Egido-Aguilera, 2019). The approach consists in a pure planning problem aimed at identifying the nominal rating of each technology that minimizes the levelized cost of electricity over a medium/long term horizon (Shaahid and Elhadidy, 2007; Deshmukh and Deshmukh, 2008; Anglani and Muliere, 2010; Geraili et al., 2014; Dong et al., 2016; Mohamed and Eltamaly, 2018). Improvements of this approach directly address the interconnection between energy and water system by identifying optimal demand side management strategies, which operate the desalination plant as a non-conventional storage technology, in order to increase RES penetration and the overall island sustainability (Kaldellis et al., 2004; Kaldellis et al., 2006; Spyrou and Anagnostopoulos, 2010; Bourouni et al., 2011; Clarke et al., 2015; Airoldi et al., 2016; Mentis et al., 2016; Segurado et al., 2016; Corsini and Tortora, 2017; Giudici et al., 2019).

Although the above mentioned studies provide effective and viable solutions for supporting the decarbonization process, the development of renewable energy systems in small Italian islands has been so far hampered by technical, economic and environmental/authorization issues (Andaloro et al., 2012; Ciriminna et al., 2016). Technical aspects concern the difficulties in balancing electricity services when a high share of intermittent renewable sources contributes to the power production. Economic issues regard the extra-cost for electricity production that national authorities pay to the local electrical operators. Placed that the lack of scale economies in such small systems inevitably generates much higher costs, it is indisputable that this mechanism does not foster initiatives for improving energy efficiency and the adoption of more sustainable power sources. Finally, tight environmental constraints limit the installable RES capacity, in some cases allowing only roof integrated PV systems or micro wind turbines.

However, the rapid technological innovation and the increasing commitment of the Italian public authorities in supporting islands decarbonization put the basis to overcome most of the technical and economic issues presented above. On the one hand, modern RES technologies, appropriately designed in combination with storage systems and demand side management strategies, allow to ensure electricity grid stability and good power quality even in such isolated and demandvariable energy systems. On the other hand, public institutions are implementing measures and actions to encourage RES investments.

As regards the technical and economic feasibility a plethora of studies have been carried out in the last decade providing practical suggestions specifically suitable for the Italian islands. 
(Corsini et al., 2005; Delvecchio et al., 2005; Andaloro et al., 2012; Gatta et al., 2018; Giudici et al., 2019). On the contrary, only few works focus on identifying effective measures for promoting RES investments (e.g., incentives mechanisms), and providing policy recommendations for further improving the islands sustainability (Antonelli and Desideri, 2014; Sanseverino et al., 2014; Ciriminna et al., 2016).

This paper makes a step forward with respect to the existing literature by proposing an integrated and comprehensive methodological framework for promoting RES development in the small Italian islands and supporting decision makers in shaping the decarbonization process. The framework is composed of two distinct phases, defined as prescriptive phase and assessment phase. The prescriptive phase consists in two technical steps that allow to identify 1) RES capacity targets tailored for each island that can simultaneously reduce both cost of the electrical production and carbon emissions, and 2) the most effective incentives for actually promoting investments on renewable energy. Based on the outcomes of the prescriptive phase, the assessment phase evaluates the effectiveness of the introduction of incentives by analyzing the temporal evolution of installed RES capacity with respect to the identified targets, eventually discussing the role of institutions, electrical operators and private investors in the decarbonization process and providing policy recommendations for further promoting renewable investments.

This methodological framework has been applied and tested in the frame of the Research program for the Italian Electrical System, in order to support the Italian Ministry of Economic Development in the definition of the steps to be taken to promote RES development in small Italian islands. Since geographic and environmental constraints characterizing the small Italian islands make PV the most promising technology (the only one in most of the islands), all the analyses performed in this study exclusively focus on PV. However, the proposed framework can be effectively applied in other island contexts considering different type of renewable technologies.

The remainder of this paper is organized as follows. Section 2 provides a detailed description of the small Italian islands. Section 3 presents the methodology and the data needed to perform each single step of the proposed framework. Section 4 shows and discusses the obtained results and Section 5 provides general conclusions, study limitations and suggestions for future research.

\section{SETTING THE CONTEXT: THE SMALL ITALIAN ISLANDS}

The study focuses on 20 islands located in the Mediterranean Sea (Figure 1). The main characteristics of these systems are reported in Table 1 in terms of both geographical indicators and data on the annual electricity production. Although on the overall we refer to them as a whole (i.e., the "Small Italian Islands"), geographically they are significantly different with respect to dimensions (the smallest hardly reaches $1.4 \mathrm{~km}^{2}$, the biggest $85 \mathrm{~km}^{2}$ ), orography (some are very flat, other volcanic and steep), distance from the coast (the nearest being less than $20 \mathrm{~km}$, the farthest more than $200 \mathrm{~km}$ ), permanent population (ranging between 100 and 14,000 inhabitants).

Nevertheless, they present some common features that well justify a common approach for studying possible ways to improve the sustainability of their energy system. First of all, since none of the islands is provided with a gas network or other easily accessible fuels distribution system, their energy system is strongly based on electricity (not considering the transport sector). Electricity, as already introduced, is supplied by one, rarely two, diesel power stations, managed by local, mostly

TABLE 1 | Main characteristics of the 20 small Italian islands.

ID

Island

Resident

\section{Capraia}

Giglio

Ponza

Ventotene

Capri

Tremiti

Alicudi

Filicudi

Lipari

Panarea

Salina

Stromboli

Vulcano

Ustica

Favignana

Levanzo

Marettimo

10 Pantelleria

11 Lampedusa

11 Linosa
Area

Protected

Area (\%)

Mean

Slope (\%)

$\begin{array}{ll}410 & 19.3\end{array}$

$1,446 \quad 21.5$

$3,360 \quad 7.6$

$\begin{array}{ll}745 & 1.4\end{array}$

$14,117 \quad 10.4$

$486 \quad 2.5$

$105 \quad 5.1$

$235 \quad 9.3$

$9,000 \quad 37.6$

$241 \quad 3.4$

$2,534 \quad 26.2$

$400 \quad 12.6$

$\begin{array}{ll}715 & 21.1\end{array}$

$1,332 \quad 8.2$

$3,407 \quad 19.8$

$208 \quad 5.8$

$\begin{array}{ll}684 & 12.4\end{array}$

\begin{tabular}{ll}
$7,846 \quad 84.8$ \\
\hline
\end{tabular}

$5,866 \quad 20.0$

$433 \quad 5.3$

100
100
99
102
57
101
99
100
100
99
100
100
100
52
100
100
100
100
99
99

100
100

99

102

57

101

99

100

100

99

100

100

100

52

100

100

100

100

99

99

41
38
35
19
51
23
69
61
37
51
55
59
36
20
11
32
61
21
9
16

41
38

35

19

51

69

61

37

51

55

36

20

11

32

61

1

16
Distance

From the coast (km)

Fact

50

21
50

50
53

27

44

130

110

47

80

80

60

40

77

19

17

40

147

225

173
PV capacity

Factor (MWh/MW/y)

Factor

1,368
1,397

1,426

1,426

1,380

1,387

1,494

1,533

1,494

1,542

1,504

1,445

1,591

1,523

1,523

1,513

1,494

1,523

1,600

1,600
Electric

Production (MWh/y) $\overline{\text { Power peak ratio (-) }}$

(n)

10,300

11,500

2,700

66,600

3,920

400

1,400

34,800

3,140

9,160

3,870

7,280

4,870

15,470

600

2040

44,170

37,660

2,800 
vertical integrated, electric companies. Secondly, all the islands are known for their natural and aesthetic value, which allowed the development of tourism-based economy. From the analysis of electricity generation data (not reported in this study), all the islands present a wide variability of demand on an annual basis, substantially corresponding to touristic fluxes. As an indicator of this variation, Table 1 reports the ratio between the summer and the winter power peak (calculated as the monthly average of daily maximum power values over the most and less touristic month, respectively). Data highlight that the demand variability is higher where permanent population is smaller (e.g., Alicudi), while in the most populated islands (e.g., Lampedusa), the variation is less intense yet significant in terms of impacts on the energy system operations.

As far as the end uses of electricity are concerned, the main share is due to household, commercial and public sectors. The industrial sector is instead usually absent, except for any presence of a desalination plant. Indeed, due to the lack or scarcity of fresh water sources, potable water must be produced from seawater desalination or supplied by vessels, especially during the touristic season. Available data suggest that only six islands have a working desalination plant connected to the grid, whose consumption represents around $30 \%$ of the total annual electric demand.

Since most of the islands lay under environmental constraints (see Table 1), the above mentioned environmental and aesthetic value also strongly influences the renewable energy potential. The main part of these territories is in fact designated as Natural Reserve of National/Regional importance, Natura 2000 sites or Important Bird Areas. Given the actual national and regional legislation, most of the available RES solutions (namely wind turbines as well as larger on-ground PV plants) have very few chance to be authorized. In addition, these technologies are further limited by economic issues due to the absence of on-site suitable infrastructures for their deployment. As a consequence, small to medium size PV plants appear to be the most promising technology to effectively invest on for improving islands sustainability.

\section{METHODS AND DATA}

We propose an integrated and comprehensive methodological framework for improving the sustainability of small Italian islands through the introduction of renewable energy sources (i.e., PV) and supporting decision makers in shaping the decarbonization process (Figure 2). The framework includes two distinct phases, namely the prescriptive phase and the assessment phase. The prescriptive phase is composed of two technical steps. The first one consists in the identification of the optimal energy system designs based on the electricity demand and the resource availability (i.e., solar radiation) characterizing each island, as well as the PV capital and operational costs. This step is essential to identify the PV capacity targets to be ideally achieved for obtaining the highest benefits in terms of both economic and environmental sustainability. The second step focuses on promoting PV investments making them

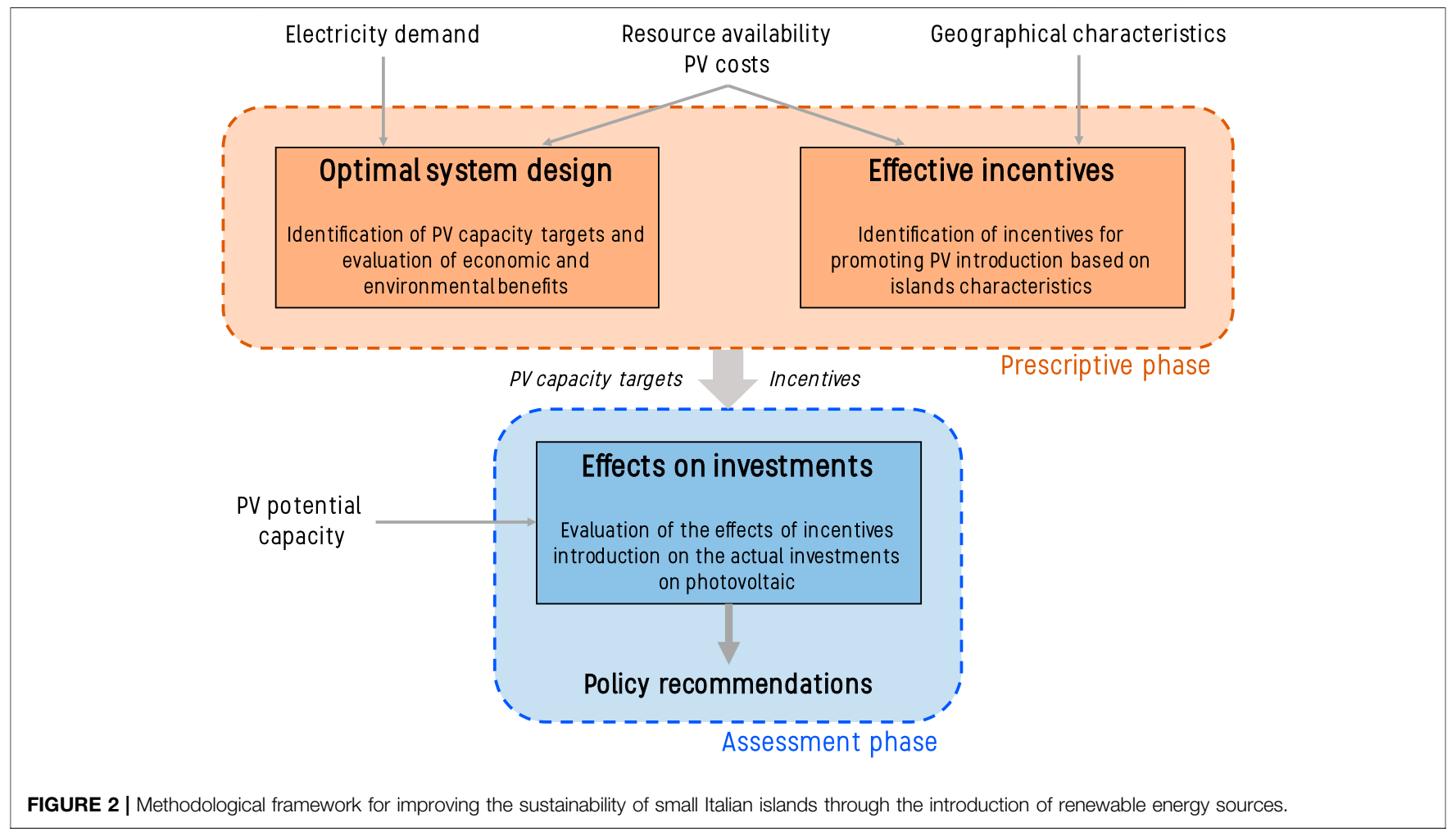


economically attractive through the definition of specific incentives calculated according to the PV power potential and the geographical characteristics (e.g., distance from the mainland, orography) of each island. Based on the outcomes of the prescriptive phase (i.e., PV capacity targets and incentives), the assessment phase evaluates the response of public and private investors to the introduction of the incentives. This is done by analyzing the time evolution of the PV installed capacity of each island compared to the target to be ideally achieved and the PV potential capacity that could be exploited according to the orography, the space availability and the environmental constraints. Finally, the role of institutions, electrical operators and private investors in the process leading to islands decarbonization is discussed, providing policy recommendations for further promoting renewable investments.

In the next sections, the methodology adopted in each step of the framework together with the data needed to perform the analyses are discussed in detail.

\subsection{Optimal System Design}

In order to identify the optimal system designs, the energy system of each island is modeled using HOMER Pro ${ }^{\circledR}$ (Hybrid Optimization Model for Multiple Energy Resources), a software developed by the National Renewable Energy Laboratory (NREL), which is widely adopted in different studies to design electricity generation systems in remote communities, through technical and economic evaluations of different renewable and conventional energy mixes (Lal et al., 2011; Vani and Khare, 2013; Singh and Chanana, 2019).

For each island, different energy system configurations coupling diesel generators with different PV capacities are simulated to cover a given observed electricity demand over a project horizon of 25 years. The optimal system configuration is the one that attains the lowest value of Levelized Cost Of Electricity (LCOE).

LCOE represents the cost for producing $1 \mathrm{kWh}$ of electricity and is calculated as the ratio between the net present cost computed over the project horizon and the total electricity production. This indicator is widely adopted for evaluating investments in the energy sector, as it accounts for all the costs occurring during the project horizon, namely investment costs, operational costs and costs for replacing the technologies when reaching the end of their life.

In addition to LCOE, each energy system configuration is also evaluated through these three additional indicators:

- RES penetration (\%). This indicator represents the percentage of the total electrical energy load covered by RES power over the entire project horizon.

- Energy surplus (\%). This indicator represents the percentage of RES energy that cannot be used for covering the load (i.e., RES power is higher than the electrical load).

- Fuel consumption (liters/y). This indicator is calculated through specific efficiency curves, which define the fuel consumed by each diesel generator as a function of its electricity output.
Finally, the optimal system configuration is compared to a business-as-usual simulation based on the existing energy system, which almost exclusively relies on diesel generators.

For the specific case study of the Ustica island, additional configurations considering the introduction of batteries (i.e., EESS, Electric Energy Storage System) and the total shutdown of diesel generators for some hours of the day are analyzed. Moreover, the effects of demand side management strategies, which exploit a desalination plant as a nonconventional storage technology, are examined. More precisely, the following system configurations are considered:

(1) "Diesel + PV." These configurations are simulated assuming that one diesel generator is always switched on and produces at least $20 \%$ of its nominal capacity, in order to guarantee stable electricity grid parameters and compensate any sudden variations of PV power production and/or of electricity demand.

(2) “Diesel + PV + Batteries (100\% PV)." These configurations are characterized by the introduction of a storage system (batteries) with a ratio 2:1 between energy and power and a roundtrip efficiency of $90 \%$. The energy size of the storage system is equal to the PV installed capacity (e.g., PV capacity = $1 \mathrm{MWp}$, storage system size $=1 \mathrm{MWh} / 500 \mathrm{~kW})$. As for the "Diesel + PV" configurations, also in this case the assumption that at least one diesel generator must be always switched on holds true, and the batteries are used for time shift only (i.e., renewable energy surplus is stored in the batteries to be released when electricity demand is higher).

(3) “PV + Batteries (100\% PV)." These configurations are based on the hypothesis that the storage system can contribute to reach the operating reserve required by the grid, by delivering or absorbing power in case of sudden changes in RES production or electricity demand. The storage system is able, in fact, to balance energy demand and supply, allowing diesel generators to be switched off for some hours of the day. Thus, when simulating these configurations, diesel generation is only used when the electrical load cannot be covered by RES or batteries. Also in this case, the energy size of the storage system is equal to the PV installed capacity.

(4) “PV + Batteries (200\% PV)." These configurations have the same characteristics of the previous ones, but, in this case, the energy size of the storage system is twice the PV installed capacity.

(5) "Diesel + PV + Water storage." These configurations have the same characteristics of "Diesel + PV" ones but, in this case, the desalination plant is managed as a non-conventional unidirectional storage technology in order to increase the flexibility of the energy system (demand side management). Drinking water can in fact be produced in the hours of the day when RES power is higher, stored in the reservoirs (already installed in the island), and released according to the water demand. In particular, the desalination plant ( $\max$ water production: $1,600 \mathrm{~m}^{3} / \mathrm{d}$ ) is treated as a deferrable load, namely an electrical load to be satisfied with a lower priority with respect to the principal load, as a given storage capacity 
is associated to it. In our case, the storage capacity of the reservoirs $\left(11,000 \mathrm{~m}^{3}\right)$ has been converted in energy capacity $(\mathrm{kWh})$ through a specific electricity consumption coefficient of the desalination plant equal to $6.07 \mathrm{kWh} / \mathrm{m}^{3}$. Simulations are performed starting from a minimum PV capacity equal to $800 \mathrm{kWp}$ in order to generate an energy surplus large enough to capture the benefits of this demand side management strategy.

Energy system simulations are performed considering technical parameters of the existing diesel generators, and of commercial technologies (i.e., PV modules, batteries), predefined system operating rules (e.g., operating reserve, diesel generators scheduling), hourly electricity demand and solar radiation profiles. Power generation data are provided by the local energy companies and refer to year 2014. Solar radiation profiles are derived from JRC-PVGIS (https://re.jrc.ec.europa.eu/ pvg_tools/en/tools.html) For further details on modeling assumptions and settings of the numerical experiments, the reader should refer to Giudici et al. (2019, 2020).

For the purpose of identifying the optimal solutions, the simulations carried out in this analysis consider the explicit costs of the energy system only, without taking into account the environmental costs resulting from the use of fossil fuel, the grid adaptation costs for enhancing the RES hosting capacity, nor any direct incentive to RES development.

\subsection{Effective Incentives}

The methodology presented in this Section has been developed to support the national regulator (ARERA - Italian Regulatory Authority for Energy, Networks and Environment) to identify effective incentives for promoting RES investments in small Italian islands. While on the mainland the incentives for RES investments are relatively easily defined based on the average market electricity price, in the case of isolated systems such as the small islands, specific conditions affecting costs and resource availability have to be necessarily considered for assessing power plants profitability and, accordingly, the economic support to promote private investments.

The proposed methodology allows to estimate effective and differentiated feed-in tariffs for the small Italian islands based on their geographical characteristics, by calculating the LCOE values of potential investments over a given incentive time horizon. As already discussed in Section 3.1, LCOE represents the net present cost for producing $1 \mathrm{kWh}$ of electricity from a specific power system (a PV plant in this case) or, in other words, the price at which the electricity generated should be sold for compensating all the costs occurring during a given time horizon, namely investment, operational and maintenance costs. LCOE value is thus strictly dependent on investment and operational costs and PV power potential, which could vary significantly from an island to another. Moreover, it is also affected by the rate adopted to discount the costs. This discount rate, called WACC (Weighted Average Cost of Capital), can be seen as an objective rate for the investor, as it estimates the cost of the capital used to finance the investment. The higher the WACC, the higher the LCOE, namely the higher the price at which the electricity should be sold in order to compensate the investment.

The first step of the proposed methodology consists in investigating the maximum range of LCOE value variation due to geographical differences between islands for different PV plant size classes, in order to verify the real need for differentiated incentives. Then, a multivariate cluster analysis is performed to identify groups of islands with similar characteristics in order to reduce the number of different feed-in tariffs. Finally, for each group of islands, a value of investment cost consistent with the average geographical characteristics of the corresponding islands is determined, and the LCOE value to be proposed as feed-in tariff is calculated for different PV plant size classes.

\subsubsection{Range of Levelized Cost of Electricity Variation}

Variables that can affect LCOE values over the incentive time horizon are investment costs and PV energy potential, which are strictly linked to the geographical characteristics of the islands. In particular, adverse logistic conditions, including high distance from the mainland and/or complex orography, are responsible for significantly higher PV plants costs. Indeed, while distance from the coast may affect the transport and maintenance costs (also due to the lack of skilled workforce available on site), the steep morphology of some islands may involve high costs for internal material transportation and, if needed, for excavation and leveling works (in case of on ground PV plants).

Focusing on PV power potential, the geographical features play a significant role as well. Since the different archipelagos are scattered from North to South in the Mediterranean Sea covering a wide range of latitudes (Figure 1), the average PV capacity factor (MWh/MW/year), calculated as the ratio between the average annual power production and the capacity of the PV plant, varies significantly among islands at different latitudes.

Based on the minimum and maximum values of investment cost (calculated by increasing the minimum and maximum market cost registered on the mainland by $10-20 \%$ in order to account for logistic hindrance) and PV capacity factor (calculated across the 20 islands according to the natural resource availability), the LCOE range of variation is computed for different PV plant size classes, considering the following extreme situations: the best extreme situation that couples the minimum investment cost with the maximum capacity factor, and the worst extreme situation that couples the maximum investment cost with the minimum capacity factor. To calculate LCOE, the following parameters are also considered:

- Plant lifetime: 20 years (reduced from the standard 25 years to account for the challenging environmental condition).

- Incentive time horizon: set equal to the plant lifetime.

- Annual degradation coefficient of PV power production: $0.8 \%$ (increased from the standard $0.5 \%$ considering a major exposition to saline atmosphere).

- Discount rate: $5.31 \%$ (value suggested by ARERA to account for the relatively high risk associated to the PV investments in small islands). 


\subsubsection{Cluster Analysis}

The final impact of the geographical characteristics on the profitability of PV plants and, consequently, on LCOE depends on the overall pattern assumed by geographical variables. Indeed, each variable can exert positive or negative effects on profitability independently from the others. For example, a southern volcanic island far from the mainland might be characterized by higher solar radiation, but also very high installation and maintenance costs. Conversely, a northern, flat island close to the coast might have a lower PV power potential, but, at the same time, lower installation and maintenance costs.

In order to investigate the pattern of the geographical features within the set of islands considered, we simultaneously analyzed three easily measurable geographical variables strictly related to costs and PV power potential, namely latitude, distance from the coast and orography. These features are quantified by the following indicators:

(1) PV capacity factor (data extracted from JRC PVGIS (https:// re.jrc.ec.europa.eu/pvg_tools/en/tools.html), ranging between 1,350 and 1,600 MWh/MW/year;

(2) Distance from the nearest commercial port (GIS based measuring), ranging between 19 and $225 \mathrm{~km}$.

(3) Average slope (calculated from Digital Terrain Model resolution $20 \times 20 \mathrm{~m}$ ), ranging between $9 \%$ and $70 \%$.

Each island is characterized by different values of these indicators, potentially resulting in 20 different LCOE values (i.e., 20 different feed-in tariffs). With the goal to reduce the number of feed-in tariffs, we thus apply a cluster analysis, a multivariate statistical method that allows to obtain groups of elements out of a data set on the basis of the relative similarity between the elements. The clustering analysis is carried out using different similarity metrics and clustering algorithms, all leading to the identification of the same groups of islands with similar combination of the three indicators explained above.

\subsubsection{Feed-In Tariff Identification}

Based on the results of the cluster analysis and the variability ranges of the investment costs, the LCOE value is calculated for each group of islands identified and for the different plant size classes considered. The PV energy production is calculated considering the average PV capacity factor of each group. As far as the investment cost is concerned, a different value was attributed to each group based on the ranges previously identified, by means of a qualitative approach based on the average values of "distance" and "slope." According with this approach, we attribute a greater weight to the orography (i.e., slope) rather than to the distance from the coast.

\subsection{Effect on Investments}

Starting from our studies on the RES potential in small Italian islands (Garofalo et al., 2014; Garofalo et al., 2015), on February $14^{\text {th }}, 2017$ the Ministry of Economic Development issued a decree: Ministerial decree, 14th February 2017. "Disposizioni per la progressiva copertura del fabbisogno delle isole minori non interconnesse attraverso energia da fonti rinnovabili" aimed at supporting the transition of small islands not connected to the national electricity grid toward a more sustainable energy system. The decree provides directions and measures for achieving three main objectives:

(1) Reaching a minimum RES capacity target within 2020.

(2) Modernizing the electric network in order to enhance the hosting capacity within 2030.

(3) Promoting the realization of innovative projects that demonstrate high reduction of conventional electricity production by implementing the integration of energy vectors or sectors.

As far as the first objective is concerned, specific RES capacity targets are defined for every single island based on the outcomes of the optimal system design step of the prescriptive phase reported in Section 4.1. Capacity targets are set in order to provide around $10 \%$ RES share as a first minimum step that is deemed to be reached also in the more disadvantaged islands. In addition to these targets, the decree provides a $5 \%$ reduction of electricity consumption to be reached through the installation of thermal solar panels or high efficiency heat pumps replacing electric boilers for hot sanitary water.

In order to promote private initiatives for reaching the above mentioned objectives, the decree identifies the need of new incentive mechanisms, specifically tailored for the small islands and possibly recognizing diversified feed-in tariffs to take into account specific peculiarities. On the basis of the prescriptive phase results reported in Section 4.1, on November $6^{\text {th }}, 2018$ ARERA issued the Resolution 558/2018/R/efr containing the "definition of the remuneration of electricity and thermal energy produced from renewable sources in noninterconnected islands." The regulation framework was eventually completed in January 2019 with the issuing by GSE (Italian Energy Services Operator) of the technical rules for accessing to the economic incentives (GSE, 2019). Meanwhile, following art. Three of the 2017 ministerial decree, each local energy operator has prepared and forwarded to ARERA a Network Development Program Report, identifying critical issues and actions needed to modernize the electricity grid in order to reach the hosting capacity target corresponding to three times the 2020 RES capacity target (i.e., Objective 2).

For evaluating the effects of the set of measures provided by the Italian Government, we analyze the temporal evolution of the installed PV capacity from before the decree to today, comparing it to the capacity target to be ideally achieved in 2020 and 2030. As a starting point we refer to the year 2014 (Garofalo et al., 2014), for which we have a complete dataset directly provided by the local energy operators (see Section 3.1). To evaluate the current situation (reference year: 2019), we examine the GSE public database (atla.gse.it) and the Network Development Program Reports prepared by the energy operators of the small islands at the end of 2017. These latter provide some development scenarios to cope with the targets set by the decree for 2020 and 2030, by assessing through indicative 
TABLE 2 | Performance indicators of the optimal "Diesel + PV" configuration for each of the five islands considered with the associated PV capacity.

\begin{tabular}{lccccc}
\hline & Ustica & Giglio & Lampedusa & Ventotene & Tremiti \\
\hline PV capacity (kWp) & 1,500 & 2,000 & 6,000 & 150 & 400 \\
LCOE reduction (\%) & 7.7 & 6 & 5 & 1 & 1 \\
RES penetration (\%) & 25.6 & 25.8 & 26.8 & 8 & 9.8 \\
Energy surplus (\%) & 26.5 & 20.5 & 8.2 & 18.8 & 58.2 \\
Fuel consumption & 26.6 & 24.5 & 25.9 & 6.8 & 8.8 \\
reduction (\%) & & & & &
\end{tabular}

surveys the PV capacity potential that might be available on the short and medium term.

\section{RESULTS AND DISCUSSION}

In this section, the obtained results for the case study of the small Italian islands are presented and discussed. In particular, Section 4.1 shows the results of the prescriptive phase and Section 4.2 focuses on the assessment phase of the methodological framework shown in Figure 2.

\subsection{Prescriptive Phase}

\subsubsection{Optimal Energy System Configurations}

Results on the optimal energy system design are shown for five islands, selected as the most representative of the 20 small Italian islands in terms of dimensions and geographical characteristics. Table 2 shows the PV capacity associated to the optimal "Diesel + PV" energy system configuration for each of the five islands considered, with the corresponding system performance in terms of LCOE and fuel consumption reduction with respect to the business-as-usual simulation, RES penetration and energy surplus. It is worth noting that for three of the five islands considered (i.e., Ustica, Giglio, Lampedusa), RES introduction is economically convenient, leading to a LCOE reduction varying from $5 \%$ to about $8 \%$ and a decrease in fuel consumption of about $25 \%$. In addition, the optimal system configurations allow to achieve a RES penetration higher than $25 \%$. For Lampedusa island (representative of the major islands among the 20 existing ones), this value is also associated to a very low energy surplus, meaning that almost all the PV power potential is effectively exploited to cover the electricity demand.

Focusing on the other two islands analyzed, namely Ventotene and Tremiti, we can observe that a low optimal PV capacity leads to a very low LCOE reduction (1\%) with respect to the businessas-usual simulation. In these cases, higher PV capacities would be not affordable, as the associated higher capital costs would not be compensated by a reduction in the operational costs expected by higher RES penetration. The additional RES power potential would be in fact entirely surplus, further increasing the already very high energy surplus. The reason of this low system performance is mainly related to the particular electricity demand profiles of these islands, which are affected by a very high seasonal variability: the demand is almost entirely concentrated in the summer touristic months with very low values registered in winter. In the current situation, at least one of the diesel generators installed in the islands must be always switched on at a minimum operating power in order to assure the continuity of the electricity generation at good quality standards. However, in the smallest islands this minimum operating power is very close to the electricity demand for most of the year. When introducing RES, this operating strategy forces to curtail PV power more frequently, leading to lower RES penetration and higher energy surplus.

The analysis performed allows to conservatively assert that, for each of the islands considered, a RES penetration of about $10 \%$ could be achieved with a relatively low effort and would lead to an environmental and economic benefit with respect to the current situation. On the one hand, RES introduction would allow to produce clean energy, reducing carbon emissions. On the other hand, lower costs for electricity generation would reduce the extra-costs the national electricity system currently pays to assure the energy services in the small islands.

Moreover, higher RES penetration values for Italian islands could be reached by coupling PV systems with batteries and by integrating the electricity system with the water system through the definition of demand side management strategies that manage desalination plants as non-conventional storage technologies. In the next Section, we analyze these solutions more in detail for the case study of the Ustica island.

\subsubsection{Deeper Insights on the Ustica Island}

Figure 3 shows the LCOE variation with respect to the businessas-usual simulation associated to different PV capacities for each of the above described energy system configurations. Focusing on the "Diesel + PV" configuration (black triangle solid line), results show that LCOE reduction increases with the PV capacity until the optimal capacity (i.e., $1,500 \mathrm{kWp}$ ) is reached. This point is characterized by a LCOE reduction and a RES penetration equal to $7.7 \%$ and $25.6 \%$, respectively, and a decrease in fuel consumption of $26.6 \%$ (Table 3). It is worth noting that beyond the optimal PV capacity, the economic benefit of installing a higher PV capacity decreases, as the corresponding higher RES power potential would be entirely surplus, avoiding to compensate the higher investment costs through a reduction in the operational ones.

If we consider a system configuration that couples PV with batteries ("Diesel + PV + Batteries (100\% PV)," we can observe that the overall economic benefit in terms of LCOE reduction is lower with respect to the "Diesel + PV" configuration, due to the hypothesis that forces diesel generators to be always switched on and the higher investment costs associated to the storage system (gray triangle dashed line). However, the introduction of the batteries allows to significantly increase the RES penetration by reducing the energy surplus, leading to a higher optimal PV capacity (1,700 kWp) (Table 3 ). In addition, exploiting RES power potential through the storage system allows to reduce diesel generation leading to a lower fuel consumption.

The highest economic benefit associated to the introduction of batteries is achieved when these latter can contribute to reach the operating reserve required by the system, allowing to switch off diesel generators for some hours of the day ["PV + Batteries (100\% PV)" - green circle solid line]. In this case, the higher the 


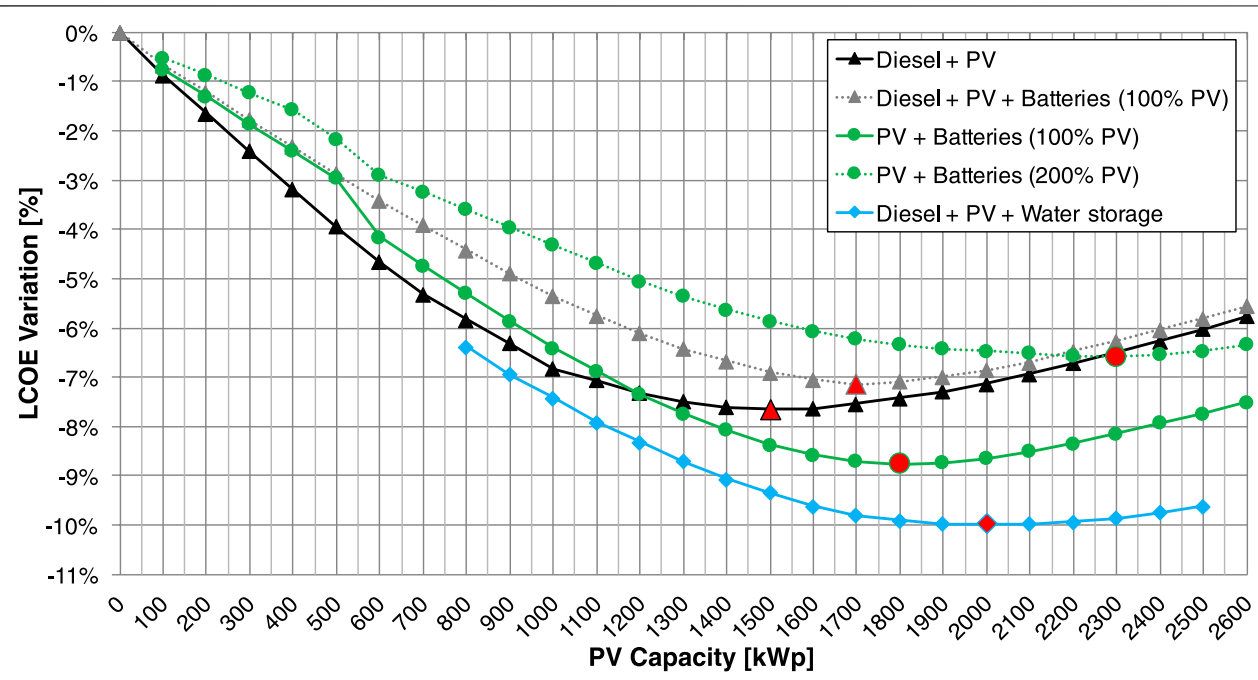

FIGURE 3 | LCOE variation with respect to the business-as-usual simulation for different "Diesel + PV," "Diesel + PV + Batteries," "PV + Batteries" and "Diesel + PV + Water storage" energy system configurations. Red markers refer to the optimal PV capacity.

TABLE 3 | Performance indicators of the optimal "Diesel + PV" (1), "Diesel + PV + Batteries (100\% PV)" (2), "PV + Batteries (100\% PV)" (3), "PV + Batteries (200\% PV)" (4), "Diesel + PV + Water storage" 5) configuration for the Ustica island with the associated PV and Battery capacity.

\begin{tabular}{lccccc} 
Configuration no & $\mathbf{1}$ & $\mathbf{2}$ & $\mathbf{3}$ & $\mathbf{4}$ & $\mathbf{5}$ \\
\hline PV capacity (kWp) & 1,500 & 1,700 & 1,800 & 2,300 & 2,000 \\
Battery capacity (kWh/kW) & - & $1,700 /$ & $1,800 /$ & $4,600 /$ & - \\
& & 850 & 900 & 2,300 & \\
LCOE reduction (\%) & 7.7 & 7.2 & 8.8 & 6.6 & 10 \\
RES penetration (\%) & 25.6 & 33.2 & 35.2 & 46.1 & 32.5 \\
Energy surplus (\%) & 26.5 & 12 & 12 & 6.9 & 11.7 \\
Fuel consumption reduction (\%) & 26.6 & 32.3 & 35.6 & 45.4 & 34.2
\end{tabular}

PV capacity and, consequently, the batteries capacity, the higher the hours when diesel generators can be switched off, leading to 1) a further reduction of fuel consumption, and 2) an increase in the operating life of diesel generators. By fully exploiting the advantages of installing the batteries, the optimal PV capacity further increases up to $1,800 \mathrm{kWp}$. This solution achieves a LCOE reduction of $8.8 \%$ and a RES penetration of $35.2 \%$, significantly improving the performance of the "PV + Diesel" configuration (Table 3).

If we focus on the "PV + Batteries (200\% PV)" configuration, we can observe that the optimal PV capacity further increases up to $2,300 \mathrm{kWp}$ (green circle dashed line). The very high capacity of the storage system (2 times the PV capacity) allows to significantly reduce the energy surplus (6.9\%), obtaining a RES penetration of $46.1 \%$ and a fuel consumption reduction of $45.4 \%$ (Table 3). However, even if this optimal solution can be considered the best one from an environmental point of view, it attains the lowest LCOE reduction (6.6\%), due to the very high investment costs associated to the high capacities of both PV and batteries.
TABLE 4 | LCOE calculated for different PV plant sizes assuming the following extreme scenarios: the best extreme scenario couples the minimum investment cost with the highest PV capacity factor; the worst extreme scenario couples the maximum investment cost with the lowest PV capacity factor.

\begin{tabular}{lccc}
$\begin{array}{l}\text { PV plant size } \\
(\mathbf{k W p})\end{array}$ & $\begin{array}{c}\text { Investment cost } \\
(\boldsymbol{\epsilon} / \mathbf{k W p})\end{array}$ & $\begin{array}{c}\text { PV capacity factor } \\
\text { (MWh/MW/year) }\end{array}$ & $\begin{array}{c}\text { LCOE } \\
\text { (€/MWh) }\end{array}$ \\
\hline $0.5 \leq \mathrm{P} \leq 6$ & 1,800 & 1,600 & 147.5 \\
& 2,400 & 1,370 & 211.4 \\
$6<\mathrm{P} \leq 20$ & 1,630 & 1,600 & 134.1 \\
& 2,200 & 1,370 & 193.8 \\
$20<\mathrm{P} \leq 200$ & 1,500 & 1,600 & 124.9 \\
$\mathrm{P}>200$ & 2,000 & 1,370 & 178.5 \\
& 1,400 & 1,600 & 116.7 \\
& 1,800 & 1,370 & 162.4
\end{tabular}

Finally, results of the "PV + Diesel + Water storage" configuration show a higher LCOE reduction for all the PV capacities considered with respect to the other system configurations (light blue diamond line). In particular, the optimal solution is characterized by a PV capacity of $2,000 \mathrm{kWp}$. The high RES power potential generated is in fact exploited by modulating the water production and, consequently, the load associated to the desalination plant, in order to maximize RES penetration and, thus reduce energy surplus (Table 3). Moreover, this solution allows to attain a higher LCOE reduction with respect to the optimal "PV + Batteries $(100 \%$ PV)" solution, as the energy time shift is, in this case, performed through modulating the load without incurring in additional investment costs for installing batteries.

\subsubsection{Effective Incentives for Promoting Photovoltaic Investments}

Table 4 shows, for four different PV plant size classes, the range of variation of the investment cost and the PV capacity factor, 


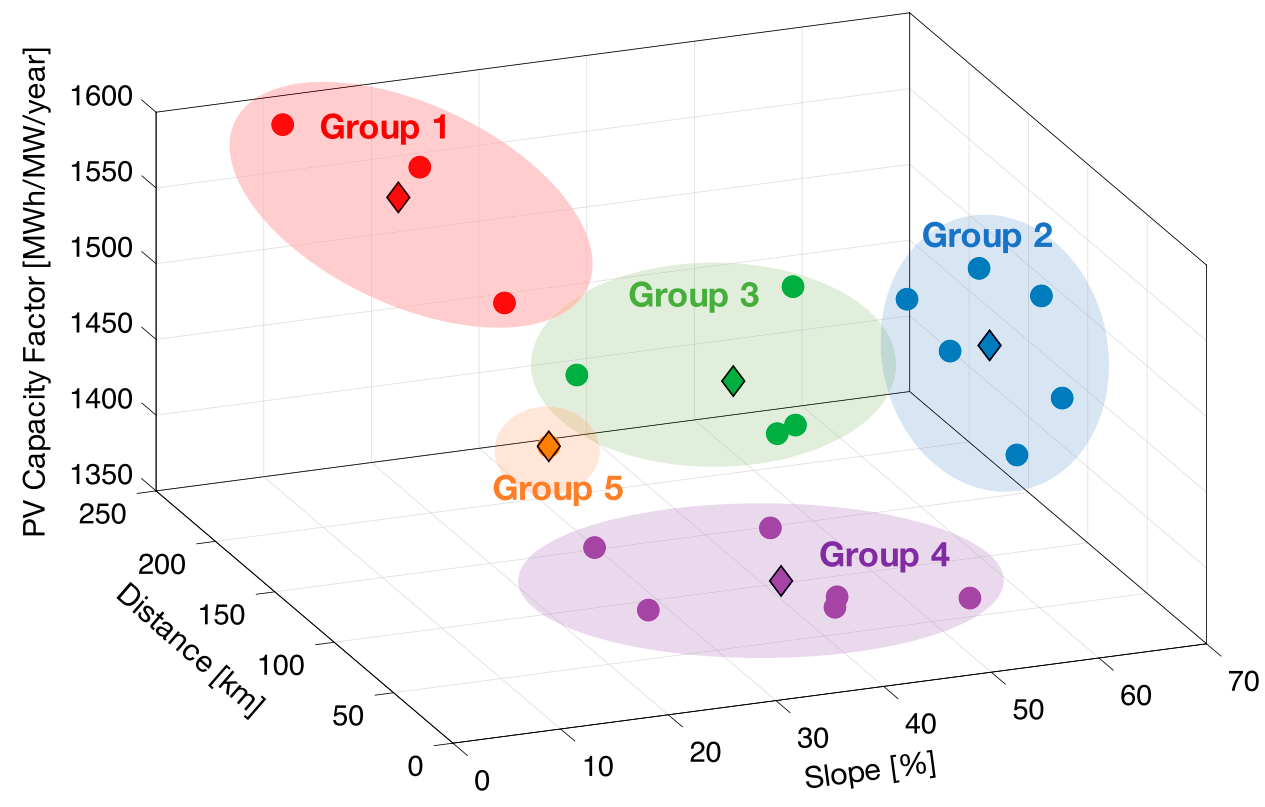

$\begin{array}{lllll}\text { Group 1 } & \text { Group 2 } & \text { Group 3 } & \text { Group 4 } & \text { Group 5 } \\ \text { Lampedusa } & \text { Alicudi } & \text { Levanzo } & \text { Capraia } & \text { Favignana } \\ \text { Linosa } & \text { Filicudi } & \text { Lipari } & \text { Capri } & \\ \text { Pantelleria } & \text { Marettimo } & \text { Ustica } & \text { Giglio } & \\ & \text { Panarea } & \text { Vulcano } & \text { Ponza } & \\ & \text { Salina } & & \text { Tremiti } & \\ & \text { Stromboli } & & \text { Ventotene }\end{array}$

FIGURE 4 | Geographical indicators calculated for the 20 small Italian islands with groups resulting from the cluster analysis highlighted. Points refer to the values of geographical indicators characterizing each island. Diamonds represent the average values of each group.

together with the LCOE value associated to the best and the worst extreme situation (see Section 3.2 for further details). It is worth noting that both minimum and maximum investment costs decrease with the size of the PV plant, making the installation of larger PV plants more economically convenient with respect to the installation of smaller ones. Results show that, at the given assumptions, geographical variability leads in the most extreme situations to a LCOE variability that ranges from $45.7 € / \mathrm{MWh}$ for big plant size (i.e., $>200 \mathrm{kWp}$ ) to $63.9 € / \mathrm{MWh}$ for small plant size (i.e., $<6 \mathrm{kWp}$ ) (Table 4), confirming the need to adopt differentiated feed-in tariffs based on the geographical characteristics of the islands.

As explained in Section 3.2 the geographical characteristics of each island are represented through three different indicators, namely the PV capacity factor, the distance from the nearest commercial port and the average slope. Figure 4 shows the values of these indicators (also reported in Table 1) for each island (points), highlighting with different colors the five groups identified via cluster analysis, as well as the average indicators values characterizing each group (diamonds). It is worth noting that group 1 is characterized by high PV capacity factors, high distances from the coast and low average slopes. Group 2 shows very high slope values, medium/low distance values and medium/high PV capacity factors. Both group 3 and group 4 show medium/low slope values and low distance values, but group 3 is characterized by higher PV capacity factors. Finally, group 5, which includes 1 island only (Favignana), shows very low slope and distance values and a medium PV capacity factor.

Based on the cluster analysis and the variability ranges of the investment costs reported in Table 4, the LCOE value is calculated for each of the five groups of islands identified and for the four plant size as explained in Section 3.2 (Table 5). It is worth noting that minimum investment costs are assigned to Favignana island (Group 5), which is flat and the closest to the coast, while maximum costs are assigned to Group 2, showing the higher average slope. Medium investment values were instead assigned to group 1,3 , and 4 .

TABLE 5 | LCOE values ( $€ / M W h$ ) representing feed-in tariffs calculated for different PV plant sizes and for the five groups of islands identified in the cluster analysis.

\begin{tabular}{lccccc}
\hline PV plant size (kWp) & \multicolumn{5}{c}{ Islands group } \\
\cline { 2 - 6 } & $\mathbf{1}$ & $\mathbf{2}$ & $\mathbf{3}$ & $\mathbf{4}$ & $\mathbf{5}$ \\
\hline $0.5 \leq \mathrm{P} \leq 6$ & 166.8 & 192.5 & 171.7 & 188.0 & 155.1 \\
$6<\mathrm{P} \leq 20$ & 152.0 & 176.7 & 156.5 & 171.4 & 141.0 \\
$20<\mathrm{P} \leq 200$ & 141.0 & 162.6 & 145.2 & 159.0 & 131.3 \\
$\mathrm{P}>200$ & 129.9 & 148.0 & 133.7 & 146.4 & 122.7
\end{tabular}



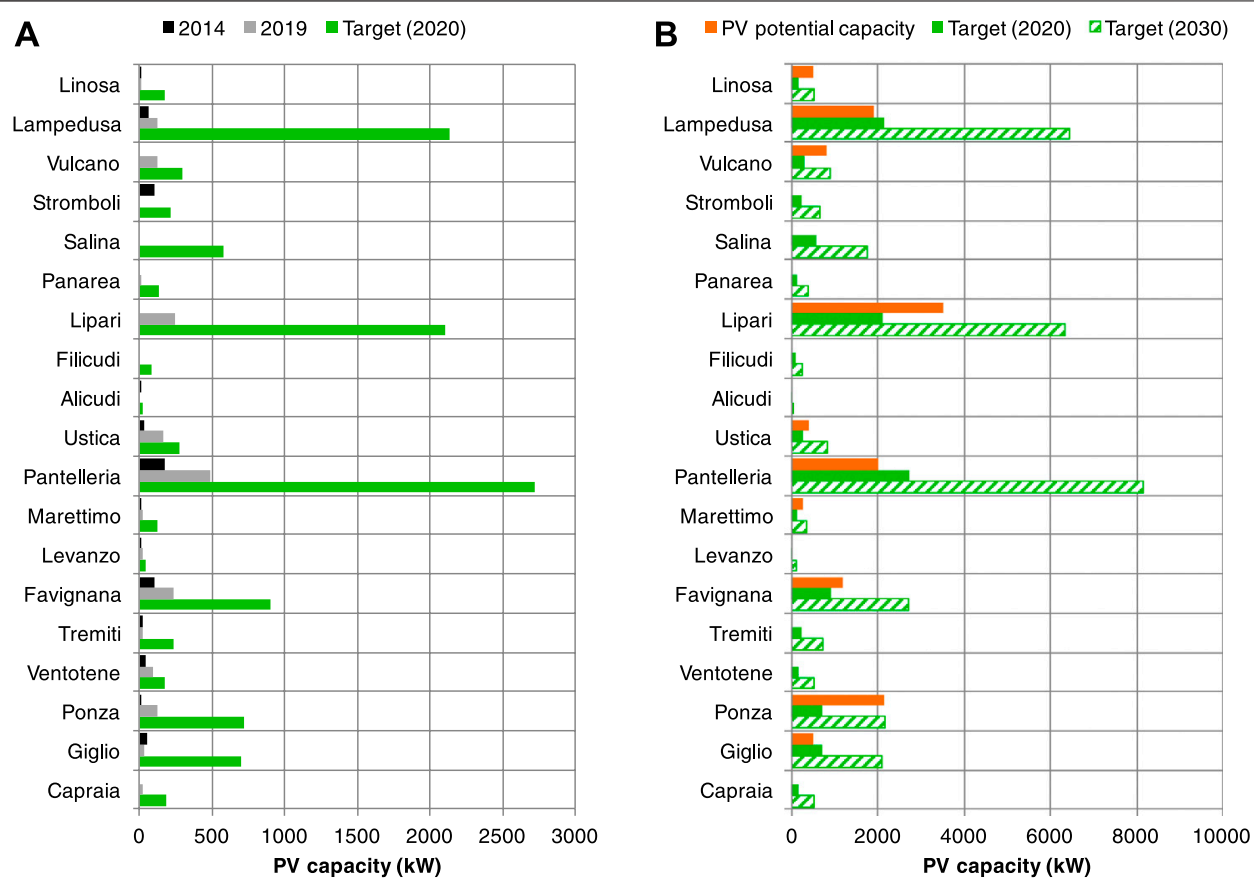

FIGURE 5 | (A) Installed PV capacity in year 2014 (pre-decree) and year 2019 (post-decree) compared with the 2020 PV capacity target. (B) Estimated PV potential capacity compared with the 2020 and 2030 PV capacity targets.

LCOE values and, consequently, feed-in tariffs vary from a minimum of $122.7 € / \mathrm{MWh}$ for big PV plants in Favignana (group 5) to $192.5 € / \mathrm{MWh}$ for small PV plants in the islands belonging to group 2. These results show that LCOE is more sensitive to the island orography and location rather than to the resource availability: the lowest values are in fact obtained for group 5, which is characterized by very low slope and distance values and a medium capacity factor. The highest LCOE values are instead obtained for group 2, which is characterized by a capacity factor almost equal to group 5, but very high slope values. According to the hypothesis adopted, islands with high slope values are in fact characterized by high investment costs. As a consequence of the adopted hypothesis, larger PV plants receive a feed-in tariff lower than small domestic plants.

\subsection{Assessment Phase}

\subsubsection{The Effects of Incentives on Photovoltaic Investments}

Figure 5A shows the installed PV capacities in 2014 (pre-decree) and 2019 (post-decree) compared with the 2020 targets set by the ministerial decree (see Section 4.1). The comparison between 2019 and 2014 shows that the situation is evolving very slowly. Although the available data might not be fully representative of the actual situation (installed capacity is to some extent underestimated), results clearly highlight that the 2020 RES capacity targets are far to be reached for most of the islands. In some cases, no RES capacity has been installed yet, or even a decrease in the installed capacity from 2014 to 2019 is registered. This result could be partially expected as the regulation framework has been recently completed, and private response could be thus delayed waiting for the new incentive tariffs. However, it must be noted that few to no investments have been realized also by the local operators, despite the decree directly prescribes their active involvement in the RES introduction process.

To better understand the reasons why even local operators have not significantly contributed to reaching the target, a deeper analysis is performed comparing the installed PV capacity with the potential capacity estimations deduced from the Network Development Plan Reports prepared by the local operators (see Section 3.3). Components contributing to the potential PV capacity are, besides the existing plants, capacity already authorized by the network operators, planned projects or simply estimated capacity that might be hosted in areas suitable to the installation of medium size PV plants. Apart from the authorized capacity, mostly represented by small plants (most likely rooftop), the PV potential identified in the surveys generally concerns areas belonging to the electricity companies (terrain around the power plant, roofs of the administrative buildings or other infrastructures) or sites already designated as industrial areas by the local spatial plans. The total estimated installable capacity is reported in Figure 5B. We can observe that, even if some islands would be able to reach the 2020 target, the potential PV capacity that local operators could ideally exploit is quite low if compared to the 2030 target. As reported by the local energy operators, this overall lack of suitable areas, in addition to prevent the RES capacity targets to be reached, significantly limits the capability to properly plan effective interventions for the electricity grid modernisation. 
As a matter of fact, the limited dimensions of the small Italian islands greatly affect the space available for the installation of "low energy density" renewable, such as PV. In addition, regional environmental laws aimed at preserving the high landscape and natural values of these islands put further constraints to space availability.

\subsubsection{Policy Recommendations}

Results presented in the previous Section clearly show that the actual PV installed capacity is very far from reaching the 2020 and, even more, the 2030 capacity targets. In summary, preliminary monitoring suggests, on the one hand, a low interest among private investors in installing PV systems and, on the other hand, a good engagement of the local energy companies. However, these latter observe a generalized lack of suitable sites due to stringent spatial plans for the deployment of industrial size PV plants. In this Section we explain the reasons behind this very low engagement, concentrating on the role of both private actors and local public operators, eventually providing suggestions and policy recommendations for further promoting renewable investments.

As far as private sector is concerned, the decree (presented in Section 3.3) recalls that extremely simplified permit procedures are in force for PV panels integrated on roofs, which are generally considered the best option in terms of environmental impact, as they avoid further land use pressure. However, even if rooftop PV power potential would in theory contribute at a large extent to reach high RES penetration in the small islands, the slow increment of the installed capacity observed up to now suggests no real interest from the private investors. In this case, the reasons are hardly to be understood without carrying out ad hoc on site social surveys (e.g., interviews to local citizens). Nonetheless, at least a couple of reasons can be envisaged to explain this apparent lack of interest. One is that, especially in the smaller islands, most of the residential constructions (including the touristic facilities) are inhabited for few months only, thus making the installation of rooftop PV plants a costly and unsustainable investment. Another reason involves the difficulties related to logistic hindrance, as the material and the skilled technicians come from the mainland. In this regard, a slow though steady diffusion of single interventions can help triggering virtuous mechanisms and accelerate the spreading of new behaviors among local citizens (Bollinger and Gillingham, 2012). In particular, the implementation within the Italian legislation and administrative framework of the recast Directive 2018/2001 (Renewable Energy Directive II, or REDII) is expected to promote the shift of the role of citizens from passive consumers to active participant through the creation of Renewable Energy Communities (RECs). To this end, the active involvement of the municipality as promoter of RECs might be a real asset to enable this transition in the small islands.

As regards PV plants other than domestic ones, the leverage to stimulate their growth consists in the creation of favourable conditions, especially concerning the authorization processes. Environmental protection goals should be reviewed taking into account the beneficial effects of reducing the use of diesel engines, not only in terms of lower environmental impact but also considering the positive impact on social and economic aspects (e.g., creation of new local jobs, expansion of economic activities in the islands, etc.) as well as on other energy related issues such as security of supply and cost of energy. In any case, these measures should take into due account the social and economic vulnerability of these very small and isolated systems.

Further actions to promote RES development should go in the direction of 1) bringing in industrial/market investors able to act in support to private subjects for exploiting the local rooftop PV potential, 2) providing a legal and administrative framework that creates favourable conditions for the experimentation of RECs, and 3) better harmonizing energy and environmental objectives among different level of governance and policy makers toward a shared strategy for the enhancement of the sustainability of the island energy systems. Finally, specific efforts should be devoted to promote the realization of desalination plants and their full integration within the electricity system in order to fully exploit the renewable power potential and improve the operations of the integrated water-energy system.

\section{CONCLUSIONS}

This paper proposes an integrated and comprehensive methodological framework for promoting RES development in small islands and supporting decision makers in shaping the decarbonization process. The framework is composed of two distinct phases, called prescriptive phase and assessment phase. The prescriptive phase allows to identify the optimal system designs and, consequently, the RES capacity targets to be ideally achieved for improving the economical and environmental sustainability of the islands, as well as the most effective incentives for actually promoting investments on renewable energy. Based on the outcomes of the prescriptive phase, the assessment phase evaluates the effectiveness of the introduction of incentives by analyzing the temporal evolution of installed RES capacity with respect to the identified targets, eventually discussing the role of institutions, electrical operators and private investors in the decarbonization process and providing policy recommendations for further promoting renewable investments. This methodological framework has been effectively applied in the frame of the Research program for the Italian Electrical System, in order to support the Italian Ministry of Economic Development in the definition of the steps to be taken to promote RES development in small Italian islands.

Results show that a RES penetration of about $10 \%$ can be ideally achieved with low effort in almost all the islands considered and that differentiated incentives are needed for promoting renewable investments in order to account for the different geographical characteristics of each island. The evaluation of the effects of recent incentives introduction shows that, even if a decree setting specific sustainability 
objectives has been issued by the regulator in 2017, almost all the 19 islands are, at this stage, far from reaching 2020 and, even more, 2030 PV capacity targets.

In summary, preliminary monitoring suggests, on the one hand, a low interest among private investors in installing PV systems and, on the other hand, a good engagement of the local energy companies, even though they observe a generalized lack of suitable sites due to stringent spatial plans for the deployment of industrial size PV plants.

Although results are really preliminary, as the access to the new incentives is quite recent, the analysis highlights that the way toward decarbonization in the small islands is difficult and should be closely monitored so as to detect the need for further measures. In such small and isolated networks, the energy system has to be carefully designed in order to allow high share of RES generation. The involvement of the local energy operators is therefore mandatory as they are the main axis around which coordinated actions can be effectively planned together with other key actors such as municipalities and water service managers.

The proposed framework constitutes a robust methodology that can be generalized to different island contexts for improving the energy system sustainability through the introduction of renewable energy sources. However, at this stage, it suffers from some limitations that mainly include the consideration of photovoltaic as the only renewable energy source, the use of stationary climate and socio-economic conditions for optimally designing the hybrid energy systems and the adoption of modeling assumptions that neglect the environmental costs (i.e., externalities of power plants emissions) and grid adaptation costs for estimating the least cost system design. Further research efforts will focus on improving the proposed framework overcoming the above mentioned limitations and on testing it in other island contexts, also considering new promising renewable technologies such as wave energy converters and offshore wind turbines.

\section{REFERENCES}

Airoldi, D., Bertani, D., Garofalo, E., Guastella, S., Lembo, E., Sandroni, C., et al. (2016). Scenari di sviluppo delle FER nelle isole minori italiane non interconnesse e analisi di casi studio. Tech. rep., RSE Rapporto RdS 17004171.

Andaloro, A. P. F., Salomone, R., Andaloro, L., Briguglio, N., and Sparacia, S. (2012). Alternative energy scenarios for small islands: a case study from salina island (aeolian islands, southern Italy). Renew. Energy. 47, 135-146

Anglani, N., and Muliere, G. (2010). "Analyzing the impact of renewable energy technologies by means of optimal energy planning," in 2010 9th international conference on environment and electrical engineering, Prague, Czech Republic, May 16-19, 2010 (IEEE), 1-5

Antonelli, M., and Desideri, U. (2014). The doping effect of Italian feed-in tariffs on the pv market. Energy Pol. 67, 583-594. doi:10.1016/j.enpol.2013.12.025.

Blechinger, P., Cader, C., Bertheau, P., Huyskens, H., Seguin, R., and Breyer, C. (2016). Global analysis of the techno-economic potential of renewable energy hybrid systems on small islands. Energy Pol. 98, 674-687. doi:10.1016/j.enpol.2016.03.043.

Blechinger, P., Seguin, R., Cader, C., Bertheau, P., and Breyer, C. (2014). Assessment of the global potential for renewable energy storage systems on small islands. Energy Procedia. 46, 325-331. doi:10.1016/j.egypro.2015.01.071.

Bollinger, B., and Gillingham, K. (2012). Peer effects in the diffusion of solar photovoltaic panels. Market. Sci. 31, 900-912. doi:10.1287/mksc.1120.0727.

\section{DATA AVAILABILITY STATEMENT}

The original contributions presented in the study are included in the article/supplementary material, further inquiries can be directed to the corresponding author/s.

\section{AUTHOR CONTRIBUTIONS}

All authors contributed to the article and approved the submitted version.

\section{FUNDING}

This work has been financed by the Research Fund for the Italian Electrical System in compliance with the Decree of Minister of Economic Development April 16, 2018.

\section{ACKNOWLEDGMENTS}

This paper reports the studies carried out by RSE S.p.A. since 2014 in the frame of the Research program for the Italian Electrical System, in order to support the Italian Ministry of Economic Development and ARERA (Italian Regulatory Authority for Energy, Networks and Environment) in the definition of the steps to be taken to promote the development of renewable energy sources in the small Italian islands. Authors would like to thank local electricity operators of the small Italian islands belonging to "Uniem" and "Enel" for their support in providing useful information for developing all the studies presented in this paper. In particular, a special thank goes to the power company "D'Anna \& Bonaccorsi" for its availability in sharing detailed data for the case study of Ustica.

Bourouni, K., Ben M’Barek, T., and Al Taee, A. (2011). Design and optimization of desalination reverse osmosis plants driven by renewable energies using genetic algorithms. Renew. Energy. 36, 936-950. doi:10.1016/j.renene.2010. 08.039 .

Ciriminna, R., Pagliaro, M., Meneguzzo, F., and Pecoraino, M. (2016). Solar energy for Sicily's remote islands: on the route from fossil to renewable energy. Int. J. Sustain. Built Environ. 5, 132-140. doi:10.1016/j.ijsbe.2016.04.003.

Clarke, D. P., Al-Abdeli, Y. M., and Kothapalli, G. (2015). Multi-objective optimisation of renewable hybrid energy systems with desalination. Energy 88, 457-468. doi:10.1016/j.energy.2015.05.065.

Corsini, A., Gamberale, M., and Rispoli, F. (2005). Assessment of renewable energy solutions in an Italian small island energy system using a transient simulation model. J. Sol. Energy Eng. 128, 237-244. doi:10.1115/1.2189870.

Corsini, A., and Tortora, E. (2017). The influence of water desalination systems on load levelling of gen-set in small off-grid islands. Energy Procedia. 142, 2230-2235. doi:10.1016/j.egypro.2017.12.623.

Delvecchio, G., Guerra, M., Lofrumento, C., and Neri, F. (2005). “A study for optimizing a stand-alone hybrid photovoltaic-diesel system to feed summer loads," In International conference on renewable energy and power quality. Spain: ICREPQ, Zaragoza, Spain, March 16-18, 2005. 167-168

Deshmukh, M. K., and Deshmukh, S. S. (2008). Modeling of hybrid renewable energy systems. Renew. Sustain. Energy Rev. 12, 235-249. doi:10.1016/j.rser. 2006.07.011. 
Dong, W., Li, Y., and Xiang, J. (2016). Optimal sizing of a stand-alone hybrid power system based on battery/hydrogen with an improved ant colony optimization. Energies 9, 785. doi:10.3390/en9100785.

Ekren, B. Y., and Ekren, O. (2009). Simulation based size optimization of a pv/wind hybrid energy conversion system with battery storage under various load and auxiliary energy conditions. Appl. Energy. 86, 1387-1394. doi:10.1016/j. apenergy.2008.12.015.

Elbaset, A. A. (2011). Design, modeling and control strategy of $\mathrm{pv} / \mathrm{fc}$ hybrid power system. J. Electrical Systems. 7, 270-286

Eras-Almeida, A. A., and Egido-Aguilera, M. A. (2019). Hybrid renewable minigrids on non-interconnected small islands: review of case studies. Renew. Sustain. Energy Rev. 116, 109417. doi:10.1016/j.rser.2019.109417.

Erdinc, O., and Uzunoglu, M. (2012). Optimum design of hybrid renewable energy systems: overview of different approaches. Renew. Sustain. Energy Rev. 16, 1412-1425. doi:10.1016/j.rser.2011.11.011.

Franzitta, V., Curto, D., Rao, D., and Milone, D. (2016). "Near zero energy island with sea wave energy: the case study of pantelleria in mediterranean sea," in OCEANS 2016-Shanghai, Shanghai, China, April 10-13, 2016 (IEEE), 1-5

Garofalo, E., Gargiulo, A., Lembo, E., Airoldi, D., Guastella, S., and Bertani, D. (2015). Studi a supporto dello sviluppo delle FER nelle isole minori. Tech. rep., RSE Rapporto RdS. 16001893.

Garofalo, E., Gargiulo, A., Lembo, E., Marazzi, R., Rondena, E., Moneta, D., et al. (2014). Sviluppo delle Fonti Energetiche Rinnovabili nelle Isole minori non interconnesse. Tech. rep., RSE Rapporto RdS. 15000371.

Gatta, F. M., Geri, A., Lauria, S., Maccioni, M., Palone, F., Portoghese, P., et al. (2018). Replacing diesel generators with hybrid renewable power plants: Giglio smart island project. IEEE Trans. Ind. Appl. 55, 1083-1092. doi:10.1109/TIA. 2018.2878155.

Geraili, A., Sharma, P., and Romagnoli, J. A. (2014). A modeling framework for design of nonlinear renewable energy systems through integrated simulation modeling and metaheuristic optimization: applications to biorefineries. Comput. Chem. Eng. 61, 102-117. doi:10.1016/j. compchemeng.2013.10.005.

Gestore Servizi Energetici (2019). Modalità Operative per il riconoscimento della remunerazione prevista dal DM 14 febbraio 2017 e dalla Deliberazione 558/ 2018/REFR.

Ghalavand, Y., Hatamipour, M. S., and Rahimi, A. (2015). A review on energy consumption of desalination processes. Desalination Water Treatment. 54, $1526-1541$

Giudici, F., Castelletti, A., Garofalo, E., Giuliani, M., and Maier, H. R. (2019). Dynamic, multi-objective optimal design and operation of water-energy systems for small, off-grid islands. Appl. Energy. 250, 605-616

Giudici, F., Castelletti, A., Giuliani, M., and Maier, H. R. (2020). An active learning approach for identifying the smallest subset of informative scenarios for robust planning under deep uncertainty, Environ. Model. Software. 127, 104681. doi:10.1016/j.envsoft.2020.104681.

Groppi, D., Astiaso Garcia, D., Lo Basso, G., and De Santoli, L. (2019). Synergy between smart energy systems simulation tools for greening small mediterranean islands. Renew. Energy. 135, 515-524. doi:10.1016/j.renene. 2018.12.043.

Ibrahim, H., Younès, R., Ilinca, A., Dimitrova, M., and Perron, J. (2010). Study and design of a hybrid wind-diesel-compressed air energy storage system for remote areas. Appl. Energy. 87, 1749-1762. doi:10.1016/j.apenergy.2009.10. 017.

Kakazu, H. (1994). Sustainable development of small island economies. Boulder, CO: Westview Press, Inc.

Kaldellis, J. K., Kavadias, K. A., and Kondili, E. (2006). Energy and clean water coproduction in remote islands to face the intermittent character of wind energy. Ijgei 25, 298-312. doi:10.1504/ijgei.2006.008997.

Kaldellis, J. K., Kavadias, K. A., and Kondili, E. (2004). Renewable energy desalination plants for the Greek islands-technical and economic considerations. Desalination 170, 187-203. doi:10.1016/j.desal.2004.01.005.

Kalogirou, S. (2005). Seawater desalination using renewable energy sources. Prog. Energy Combust. Sci. 31, 242-281. doi:10.1016/j.pecs.2005.03.001.

Kougias, I., Szabó, S., Nikitas, A., and Theodossiou, N. (2019). Sustainable energy modelling of non-interconnected mediterranean islands. Renew. Energy. 133, 930-940. doi:10.1016/j.renene.2018.10.090
Kristoferson, L., O'Keefe, P., and Soussan, J. (1985). Energy in small island economies. Ambio 242-244.

Lal, D. K., Dash, B. B., and Akella, A. (2011). Optimization of pv/wind/microhydro/diesel hybrid power system in homer for the study area. Int. J. Elect. Eng. Informat. 3, 307. doi:10.15676/ijeei.2011.3.3.4

Larsen, G. K. H., Van Foreest, N. D., and Scherpen, J. M. A. (2014). Power supplydemand balance in a Smart Grid: an information sharing model for a market mechanism. Appl. Math. Model. 38, 3350-3360. doi:10.1016/j.apm.2013.11.042.

Mentis, D., Karalis, G., Zervos, A., Howells, M., Taliotis, C., Bazilian, M., et al. (2016). Desalination using renewable energy sources on the arid islands of south aegean sea. Energy 94, 262-272. doi:10.1016/j.energy.2015.11.003.

Merino, J., Veganzones, C., Sanchez, J. A., Martinez, S., and Platero, C. A. (2012). Power system stability of a small sized isolated network supplied by a combined wind-pumped storage generation system: a case study in the canary islands. Energies 5, 2351-2369. doi:10.3390/en5072351.

Mohamed, M. A., and Eltamaly, A. M. (2018). "A pso-based smart grid application for optimum sizing of hybrid renewable energy systems," in Modeling and simulation of smart grid integrated with hybrid renewable energy systems (Springer). 53-60

Sanseverino, E. R., Sanseverino, R. R., Favuzza, S., and Vaccaro, V. (2014). Near zero energy islands in the mediterranean: supporting policies and local obstacles. Energy Policy. 66, 592-602. doi:10.1016/j.enpol.2013.11.007

Segurado, R., Madeira, J. F. A., Costa, M., Duić, N., and Carvalho, M. G. (2016). Optimization of a wind powered desalination and pumped hydro storage system. Appl. Energy. 177, 487-499. doi:10.1016/j.apenergy.2016.05.125.

Shaahid, S. M., and Elhadidy, M. A. (2007). Technical and economic assessment of grid-independent hybrid photovoltaic-diesel-battery power systems for commercial loads in desert environments. Renew. Sustain. Energy Rev. 11, 1794-1810. doi:10.1016/j.rser.2006.03.001.

Singh, S., and Chanana, S. (2019). Optimization and economic analysis of standalone hybrid pv-biomass-hydel energy system using homer. Int. J. Comput. Network Technol. 7. doi:10.12785/ijent/070203

Spyrou, I. D., and Anagnostopoulos, J. S. (2010). Design study of a stand-alone desalination system powered by renewable energy sources and a pumped storage unit. Desalination 257, 137-149. doi:10.1016/j.desal.2010.02.033.

Tselepis, S., Sorokin, A., and Olivier, G. (2001). "Gradual introduction of photovoltaic systems in Greek, Italian and French island utility grids," in 17th European photovoltaic solar energy conference, Munich, Germany, October 22-26, 2001. 914-918

Vani, N., and Khare, V. (2013). Rural electrification system based on hybrid energy system model optimization using homer. Can. J. Basic Appl. Sci. 1, 19-25

Voivontas, D., Arampatzis, G., Manoli, E., Karavitis, C., and Assimacopoulos, D. (2003). Water supply modeling towards sustainable environmental management in small islands: the case of paros, Greece. Desalination 156, 127-135. doi:10.1016/s0011-9164(03)00335-7.

Weisser, D. (2004). On the economics of electricity consumption in small island developing states: a role for renewable energy technologies? Energy Pol. 32, 127-140. doi:10.1016/s0301-4215(03)00047-8.

Zafirakis, D., Notton, G., Darras, C., Nivet, M., Kondili, E., and Kaldellis, J. (2016). "The role of renewable energy sources in solving energy and water problems of mediterranean sea islands," in Renewable energy in the service of mankind (Springer). Vol. II, 195-203

Zuccaro, C., and Guastella, S. (2001). Sostenibilità ambientale nelle Isole Minori: potenzialità di penetrazione di sistemi ad energia rinnovabile ed altre tecnologie per il contenimento delle richiesta energetica. Tech. rep., CESI Rapporto RdS. A1. 039977.

Conflict of Interest Statement: The authors declare that the research was conducted in the absence of any commercial or financial relationships that could be construed as a potential conflict of interest.

Copyright $\odot 2020$ Garofalo, Giudici and Guastella. This is an open-access article distributed under the terms of the Creative Commons Attribution License (CC BY). The use, distribution or reproduction in other forums is permitted, provided the original author(s) and the copyright owner(s) are credited and that the original publication in this journal is cited, in accordance with accepted academic practice. No use, distribution or reproduction is permitted which does not comply with these terms. 